\title{
Production of Odd Nitrogen in the Stratosphere and Mesosphere: An Intercomparison of Source Strengths
}

\author{
C. H. Jackman, J. E. Frederick, and R. S. Stolarski
}

Laboratory for Planetary Atmospheres, NASA/Goddard Space Flight Center, Greenbelt, Maryland 20771

\begin{abstract}
This study intercompares several sources of odd nitrogen (ON) in the stratosphere and mesosphere (middle atmosphere) so as to place galactic cosmic rays (GCRs), nuclear explosions, lightning, solar proton events (SPEs), relativistic electron precipitation, meteors, and the downward diffusion of NO from the thermosphere in their proper context relative to the oxidation of nitrous oxide. Use of published measurements of $\mathrm{O}_{3}$ and $\mathrm{N}_{2} \mathrm{O}$ show that the source of $\mathrm{ON}$ owing to the reaction of $\mathrm{O}\left({ }^{\prime} D\right)+\mathrm{N}_{2} \mathrm{O}$ peaks between 25 and $35 \mathrm{~km}$ and is by far the largest source in an annually, globally averaged sense with a magnitude of $4.5 \times 10^{34}$ molecules $\mathrm{yr}^{-1}$. At solar minimum the GCRs add about the same amount of $\mathrm{ON}$ as $\mathrm{N}_{2} \mathrm{O}$ oxidation $\left(1.7 \times 10^{33}\right.$ molecules $\left.\mathrm{yr}^{-1}\right)$ for geographic latitudes greater than $50^{\circ}$. Nuclear explosions in 1961 and 1962 added 1.1 and $2.2 \times 10^{34}$ NO molecules, respectively, to the total global ON content. SPEs produced more $\mathrm{ON}$ at latitudes above $50^{\circ}$ than did $\mathrm{N}_{2} \mathrm{O}$ oxidation for the years $1958,1959,1960$, and 1972. Analysis of available measurements shows the downward flux of NO from the thermosphere to be between 8 and 33\% of the integrated $\mathrm{N}_{2} \mathrm{O}$ source. Large variations in measurements of $\mathrm{ON}$ should be expected at geographic latitudes above $50^{\circ}$ where the highly variable SPE source of ON is substantial. Because of the long lifetime of $O N$ in the middle atmosphere, significant variations in its content may also be expected to occur at mid-latitudes.
\end{abstract}

\section{INTRODUCTION}

The odd nitrogen (including $\mathrm{N}, \mathrm{NO}, \mathrm{NO}_{2}, \mathrm{NO}_{3}, \mathrm{~N}_{2} \mathrm{O}_{5}$, and $\mathrm{HNO}_{3}$ ) budget of the stratosphere and mesosphere has received considerable attention owing to its relevance in the ozone balance [Crutzen, 1970, 1971; Johnston, 1971; Brasseur and Nicolet, 1973; McConnell and McElroy, 1973; Crutzen et al., 1975; Johnston et al., 1979] and in the formation of the ionospheric $D$ region [Bates, 1952; Nicolet, 1955, 1960; Strobel et al., 1970; Strobel, 1971]. Because the major nitrogen containing gas in the atmosphere, $\mathbf{N}_{2}$, has no optically allowed transitions connecting the ground and repulsive states it is extremely transparent to radiation. Although predissociation occurs in the thermosphere at wavelengths between 80 and 100 $\mathrm{nm}$ [Strobel et al., 1976], there is no photodissociation of $\mathrm{N}_{2}$ in the middle atmosphere here defined as the stratosphere and mesosphere. Production of ON thus occurs via a variety of somewhat less obvious mechanisms.

Stratospheric ON is produced mainly from nitrous oxide $\left(\mathrm{N}_{2} \mathrm{O}\right)$, which is produced in the biospheric nitrogen cycle and transported up from the earth's surface [Bates and Hays, 1967; Nicolet and Peetermans, 1972]. In the stratosphere, $\mathrm{N}_{2} \mathrm{O}$ is photodissociated to produce $N_{2}$ but also reacts with $O\left({ }^{1} D\right)$ atoms produced in photolysis of $\mathrm{O}_{3}$ to produce NO [Nicolet, 1971; Crutzen, 1970, 1971; McElroy and McConnell, 1971].

$$
\begin{aligned}
& \mathrm{O}\left({ }^{1} D\right)+\mathrm{N}_{2} \mathrm{O} \rightarrow 2 \mathrm{NO} \\
& k_{1}=5.5 \times 10^{-11} \mathrm{~cm}^{3} \mathrm{~s}^{-1}
\end{aligned}
$$

This and all other reaction rate coefficients are taken from Hudson [1977] unless otherwise noted. Figure 1 illustrates the altitude regions where this ON source, as well as several others, are efficient. Although each ON source operates over a larger altitude range than indicated in Figure 1, only that altitude region where the source has at least $10 \%$ of its peak magnitude is included. The large and relatively constant source from nitrous oxide is used throughout this paper as a basis for

\footnotetext{
Copyright (C) 1980 by the American Geophysical Union.
}

comparison of the other sources which are generally more sporadic and frequently limited in spatial extent.

These other sources include the dissociation of $\mathrm{N}_{2}$ and ion chemistry associated with solar proton events, SPEs [Crutzen et al., 1975; Frederick, 1976], galactic cosmic rays, GCRs [Warneck, 1972; Nicolet, 1975a], and relativistic electron precipitations, REPs [Thorne, 1977]. As indicated in Figure 1, a hard spectrum SPE will influence the entire middle atmosphere, from 15 up to $85 \mathrm{~km}$. The GCRs produce ON mostly below $40 \mathrm{~km}$ while REPs are influential as an ON source above $\sim 60 \mathrm{~km}$. Nuclear explosions, affecting the $\sim 7-30 \mathrm{~km}$ regime, cause sufficiently high temperatures that thermal decomposition of $\mathrm{N}_{2}$ and $\mathrm{O}_{2}$ occurs followed by the formation of NO [Johnston et al., 1973; Foley and Ruderman, 1973; Gilmore, 1975]. Lightning strokes produce $O N$ in a similar manner [Griffing, 1977; Chameides et al., 1977], however, they form odd nitrogen only below the tropopause where it is efficiently removed by rainfall. Ablating meteoroids are a constant source of ON through high-temperature reactions of air in their continuum wake [Park and Menees, 1978] but their major ON contribution is above $80 \mathrm{~km}$. Thermospheric ion chemistry is an efficient source of nitric oxide and leads to a downward flux at the mesopause [Strobel et al., 1970; Strobel, 1971; Rusch, 1973]. This has important mesospheric consequences but is efficiently screened from the stratosphere by NO photolysis.

This work intercompares several of the ON sources in the middle atmosphere with the goal of placing the SPEs, GCRs, REPs, nuclear explosions, lightning, meteors, and downward flux from the thermosphere in their proper context in relation to the ambient source associated with $\mathrm{N}_{2} \mathrm{O}$. In doing this we use available atmospheric measurements whenever possible. The SPEs are of particular interest since much study has been devoted to the unusually large event of August 1972, but little has been done toward examining the relevance of this $O N$ production over long time periods. To provide a realistic assessment of this source, we estimate the total $O N$ produced by SPEs per year for the period 1954-1979. 


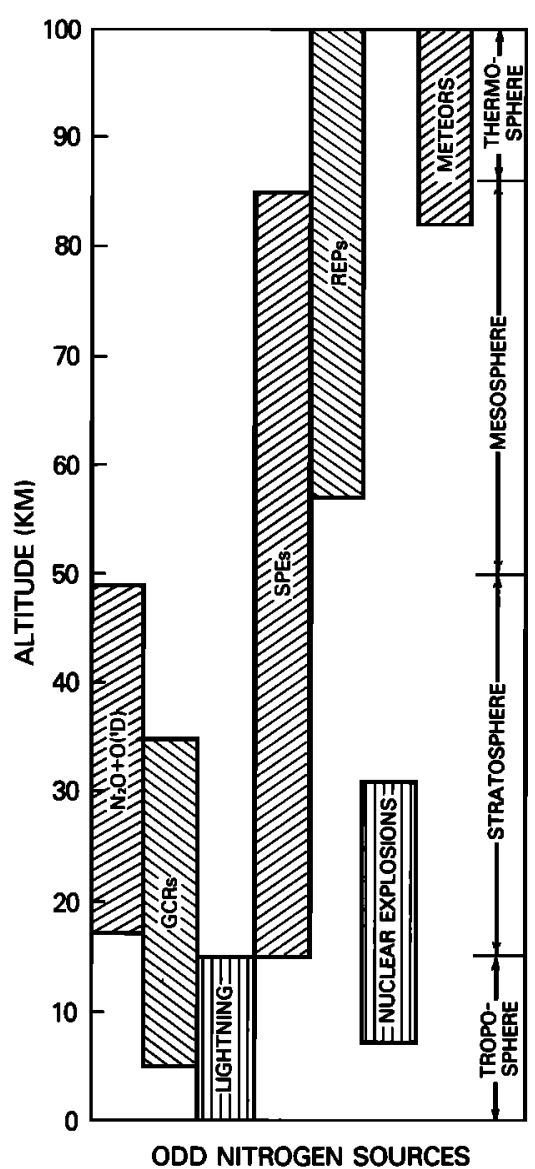

Fig. 1. Altitude region of influence from several odd nitrogen sources. These sources include the oxidation of nitrous oxide $\left(\mathrm{N}_{2} \mathrm{O}+\right.$ $O\left({ }^{1} D\right)$ ), galactic cosmic rays (GCRs), lightning, meteors, solar proton events (SPEs), nuclear explosions, and relativistic electron precipitations (REPs).

\section{Odd Nitrogen SOURCE From $\mathrm{N}_{2} \mathrm{O}$ Oxidation}

Derivation of the odd nitrogen source from $\mathrm{N}_{2} \mathrm{O}$ oxidation requires a knowledge of $\mathrm{N}_{2} \mathrm{O}$ and $\mathrm{O}\left({ }^{1} D\right)$ as a function of season, latitude, and altitude. To do this we use the method of instantaneous rates described by Johnston and Whitten [1975] which is based on empirically determined $\mathrm{N}_{2} \mathrm{O}$, and we compute $O\left({ }^{1} D\right)$ from measured solar fluxes, cross sections, quantum yields, and ozone profiles. Altitude dependent profiles of $\mathrm{N}_{2} \mathrm{O}$ at several latitudes have been measured by Fabian $e t$ al. [1979a] and by Schmeltekopf et al. [1977] and Goldan et al. [1980]. The magnitude of the $\mathrm{N}_{2} \mathrm{O}$ densities given in these three papers agree fairly well in the 40 to $45^{\circ}$ latitude range. Since the data of Schmeltekopf et al. [1977] and Goldan et al. [1980] are self-consistent, we have used these papers to derive the $\mathrm{N}_{2} \mathrm{O}$ profiles.

Seasonal data are only available at a few middle latitudes, while complete latitudinal coverage is available only in the fall. We thus had to make several assumptions to extrapolate the available data base. The following are the assumptions:

1. $0^{\circ}-10^{\circ}$ latitude; use the fall data at $5^{\circ}$ of Goldan et al. [1980] and assume no seasonal change.

2. $10^{\circ}-30^{\circ}$ latitude; use the spring data at $9^{\circ}$ of Goldan et al [1980] and Schmeltekopf et al. [1977] and assume no seasonal change.

3. $30^{\circ}-50^{\circ}$ latitude; use seasonal data from all three sources quoted above. Winter and spring profiles were so similar that they were assumed identical. Summer and fall pro- files were similar and both larger than the winter-spring profile.

4. $50^{\circ}-70^{\circ}$ latitude; use spring data at $63^{\circ}$ and summer data at $51^{\circ}$ from Schmeltekopf et al. [1977] and assume winter the same as spring and fall the same as summer.

5. $70^{\circ}-90^{\circ}$ latitude; use summer data of Goldan et al. [1980] at $78^{\circ}$ and $90^{\circ}$ and assume no seasonal change.

6. Above altitude of highest data assume the $\mathrm{N}_{2} \mathrm{O}$ mixing ratio decreases with a constant scale height. Although details of the assumed extrapolation are important to eddy coefficient determination [see Johnston et al., 1979], they have little effect on column integrated odd nitrogen production.

Johnston et al. [1979] have also recently calculated instantaneous $\mathrm{NO}$ production rates from $\mathrm{N}_{2} \mathrm{O}$ oxidation. They established $\mathrm{N}_{2} \mathrm{O}$ profiles as a function of latitude and season which are similar to ours up to an altitude of $35 \mathrm{~km}$ except at $60^{\circ}$ latitude. We used the data taken at Saskatchewan $\left(51^{\circ} \mathrm{N}\right)$ in $\mathrm{Au}-$ gust 1975 [Schmeltekopf et al., 1977], which Johnston et al. [1979] rejected as inconsistent to establish the $60^{\circ} \mathrm{N}_{2} \mathrm{O}$ profile. Our $\mathrm{N}_{2} \mathrm{O}$ mixing-ratio contours thus differ qualitatively with those of Johnston et al. [1979] by having a rather sharp dip around $60^{\circ}$ latitude. It is not clear which is correct but for the purpose of globally integrated source comparisons in this paper the differences are insignificant.

The other crucial factor in obtaining odd-nitrogen production rates is the $O\left(^{\prime} D\right)$ concentration. We used a calculation involving the multiple scattering of sunlight [Herman, 1979], diurnal averaging (Rundel [1977] for latitudes below $60^{\circ}$, and J. R. Herman, private communication, 1979 , for latitudes at and above $60^{\circ}$ ), solar irradiance [Nicolet, 1975b], $O_{3}$ seasonal profiles [Dütsch, 1974; London et al., 1977], $\mathrm{O}_{3}$ absorption cross sections [Ackerman, 1971], quantum yields from Nicolet [1975b] for the photolysis reaction

$$
\mathrm{O}_{3}+h \nu(\lambda<3100 \AA) \rightarrow \mathrm{O}_{2}+\mathrm{O}\left({ }^{1} D\right)
$$

and the $O\left({ }^{1} D\right)$ quenching reactions

$$
\begin{aligned}
& \mathrm{O}\left({ }^{1} D\right)+\mathrm{N}_{2} \rightarrow \mathrm{O}+\mathrm{N}_{2} \\
& k_{3}=2.0 \times 10^{-11} \exp (107 / T) \mathrm{cm}^{3} \mathrm{~s}^{-1}
\end{aligned}
$$

and

$$
\begin{aligned}
& \mathrm{O}\left({ }^{\prime} D\right)+\mathrm{O}_{2} \rightarrow \mathrm{O}+\mathrm{O}_{2} \\
& k_{4}=2.9 \times 10^{-11} \exp (67 / T) \mathrm{cm}^{3} \mathrm{~s}^{-1}
\end{aligned}
$$

to derive the $O(' D)$ profiles.

Using the $\mathrm{N}_{2} \mathrm{O}$ and $\mathrm{O}\left({ }^{\prime} D\right)$ profiles, we derive diurnally averaged NO production rate profiles for the four seasons at the five latitudes of $0^{\circ}, 20^{\circ}, 40^{\circ}, 60^{\circ}$, and $80^{\circ}$. Figures 2 and 3 present the final results. Peak production in spring-fall is at 30 $\mathrm{km}$ and latitude $0^{\circ}$ with a rate of $370 \mathrm{NO}$ molecules $\mathrm{cm}^{-3}$ $\mathrm{s}^{-1}$. In the winter-spring results, production ceases poleward of $60^{\circ}$, and a peak of $325 \mathrm{NO}$ molecules $\mathrm{cm}^{-3} \mathrm{~s}^{-1}$ occurs at latitude $0^{\circ}$.

There is a large uncertainty associated with the results, especially at $60^{\circ}$ and above due to the necessity of using an incomplete data set to establish a two-dimensional production rate distribution. Clearly, more experiments should be undertaken in the high and low latitude regions to provide better seasonal $\mathrm{N}_{2} \mathrm{O}$ profile information.

\section{ON Source From Particle Precipitation}

Both solar and galactic cosmic rays deposit much of their energy in the middle atmosphere. The more energetic galactic cosmic rays (GCRs) penetrate lower and deposit most of their 


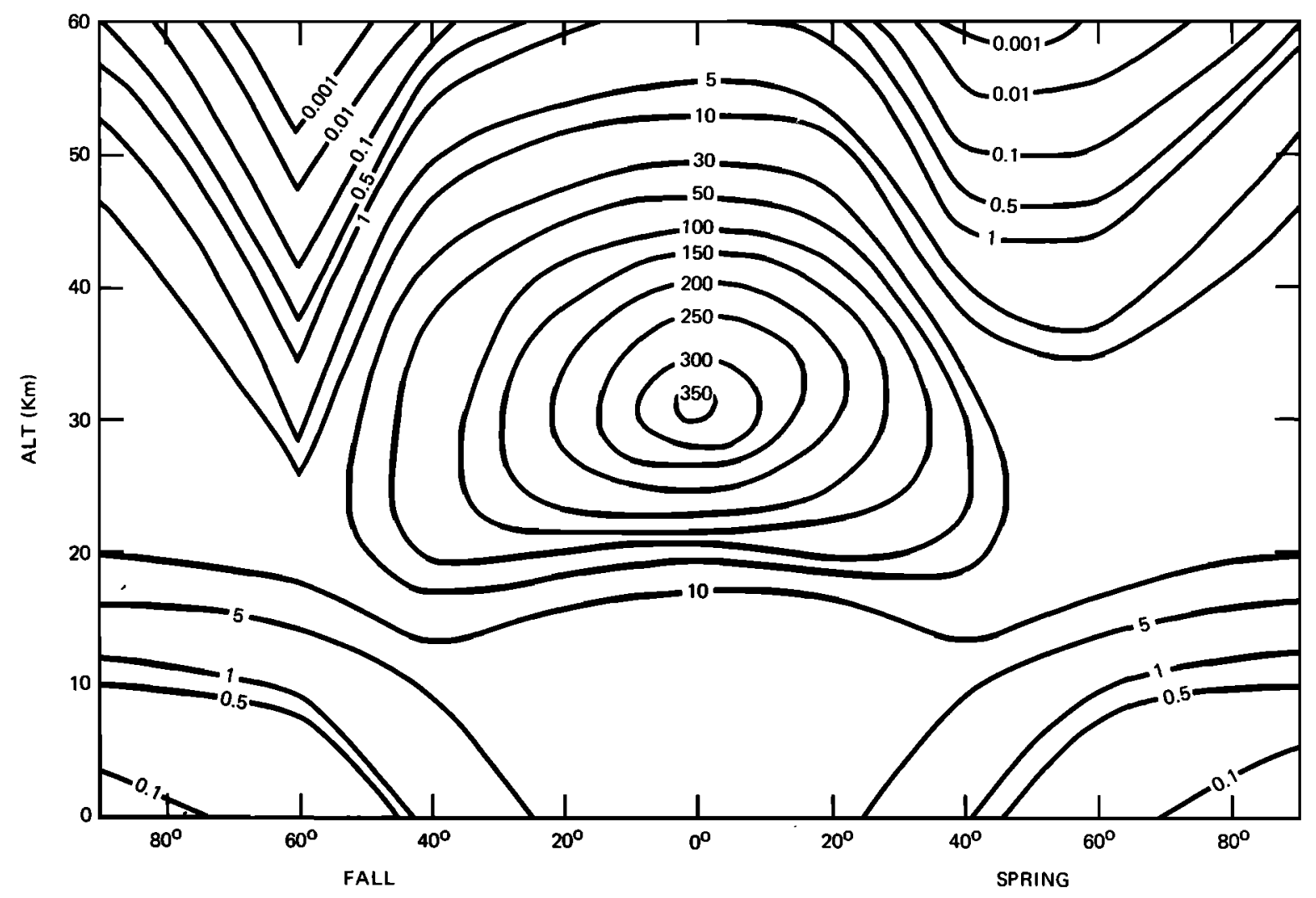

Fig. 2. Instantaneous nitric oxide production rate contours $\left(\mathrm{cm}^{-3} \mathrm{~s}^{-1}\right)$ from the oxidation of nitrous oxide for fall and spring.

energy below about $30 \mathrm{~km}$. The solar particles consist primarily of protons in the $\mathrm{MeV}$ region which occur sporadically and deposit most of their energy between 20 and $100 \mathrm{~km}$. These sporadic events are frequently referred to as solar-proton events (SPEs) or as polar cap absorptions (PCAs). Nicolet [1975a] calculated the amount of ON produced by GCRs in the stratosphere and mesosphere. He assumed that one NO molecule was produced per ion pair. Several papers [Porter et al., 1976; Frederick, 1976; Jackman et al., 1979] have since recommended 1.2-1.3 NO molecules per ion pair as more likely, and we have therefore used Nicolet's [1975a] production rates multiplied by 1.25 .

The effects of individual solar proton events (SPEs) on the atmosphere have been studied in detail [Reid, 1961; Weeks et al., 1972; Swider and Keneshea, 1973; Crutzen et al., 1975; Frederick, 1976; Heath et al., 1977; Reagan et al., 1978; Fabian et al., 1979b]. Both the total energy flux and the hardness of the spectrum are important in determining the effects of SPEs on the atmospheric ON content. High-energy protons $(E \geqslant 30$ $\mathrm{MeV}$ ) penetrate into the stratosphere while lower energies influence only the mesosphere. The lifetime of ON below the stratopause is significantly longer than at higher altitudes where dissociation of nitric oxide followed by recombination is efficient. Hence, for a given total energy input, the ON column abundance will show a greater increase for a harder energy spectrum. The appendix describes the information available and how we used that data to determine ON production rates from all of the known SPEs from 1954 through 1979.

We have used the information in the appendix to compute the instantaneous maximum ON production rate for three separate events: July 12, $1961\left(0.06\right.$ ergs $\left.\mathrm{cm}^{-2} \mathrm{~s}^{-1}\right)$; February 25, 1969 (0.04 ergs cm $\left.\mathrm{cm}^{-2}\right)$; and August 4, $1972\left(7 \mathrm{ergs} \mathrm{cm}^{-2}\right.$ $\left.\mathrm{s}^{-1}\right)$. The duration of production rates of this magnitude varies considerably and could be a few hours to a couple of days. Figure 4 compares these instantaneous rates with the GCR source above $60^{\circ}$ geomagnetic latitude at solar maximum and minimum and also with the production from $\mathrm{N}_{2} \mathrm{O}$ at both the $60^{\circ}$ and $80^{\circ}$ geographic latitudes. The production of NO from $\mathrm{N}_{2} \mathrm{O}$, as computed by Johnston et al. [1979] at $60^{\circ}$ summer, is included as well. The SPE production rate falls off rapidly below $60^{\circ}$ geomagnetic latitude due to the geomagnetic cutoff, so that SPEs directly affect only the area of the earth above about $50^{\circ}$ geographic latitude. The July 12,1961 , event illustrates a moderate SPE with a relatively soft energy spectrum (i.e., a predominance of low-energy protons). Its energy is deposited mainly in the mesosphere. The February 25, 1969, event is also a moderate one but with a harder spectrum of proton energies. It thus penetrates to stratospheric altitudes where the loss processes for $\mathrm{ON}$ are quite slow. The production rates from this very small event are seen to be comparable to the $O\left({ }^{\prime} D\right)+\mathrm{N}_{2} \mathrm{O}$ source of $\mathrm{ON}$ at high latitudes for the duration of the event. Events of this magnitude can make a significant contribution to the annual high-latitude $\mathrm{ON}$ budget. The extreme case is the August 4, 1972, SPE which is also shown in Figure 4 and has been discussed in some detail by Crutzen et al. [1975], Heath et al. [1977], and Reagan et al. [1978].

We have summed the contribution of the individual SPEs in annual intervals for the years from 1954 through 1979 by a method described in the appendix. Since these SPEs directly influence only high latitudes, the total annual production rates of ON from SPEs, GCRs, and $\mathrm{N}_{2} \mathrm{O}$ in the stratosphere and mesosphere have been integrated over latitudes above $50^{\circ}$ and are shown in Figure 5. As can be seen, the contributions due 


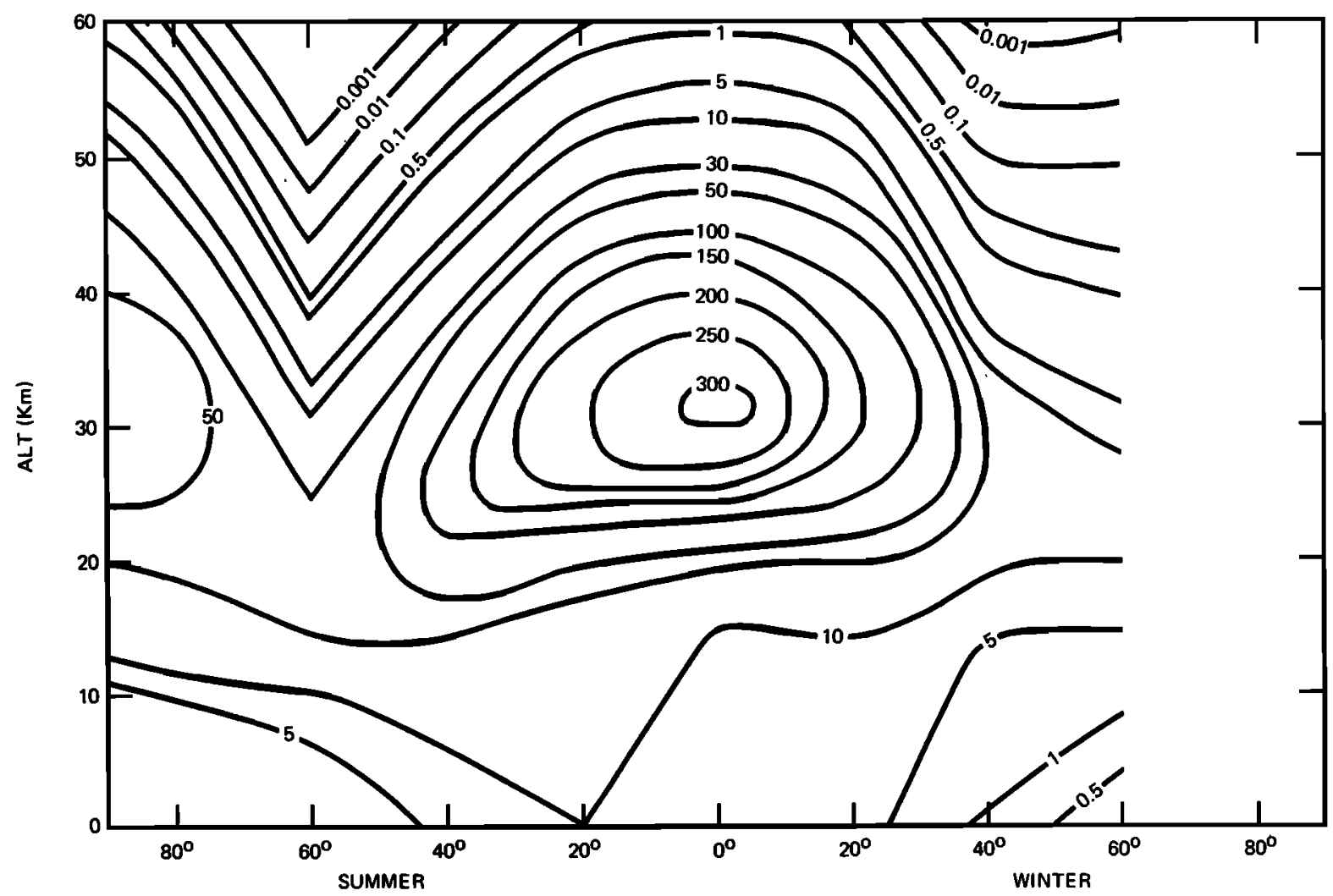

Fig. 3. Instantaneous nitric oxide production rate contours $\left(\mathrm{cm}^{-3} \mathrm{~s}^{-1}\right)$ from the oxidation of nitrous oxide for summer and winter.

to $\mathrm{GCRs}$ and $\mathrm{N}_{2} \mathrm{O}$ oxidation are comparable and relatively constant, the GCR source varying from $1.6 \times 10^{33} \mathrm{NO}$ molecules $\mathrm{yr}^{-1}$ at solar minimum down to $1.1 \times 10^{33} \mathrm{NO}$ molecules $\mathrm{yr}^{-1}$ at solar maximum with the $\mathrm{N}_{2} \mathrm{O}$ oxidation source at $1.4 \times$ $10^{33} \mathrm{NO}$ molecules $\mathrm{yr}^{-1}$. The SPE contribution is highly variable, being entirely negligible in some years while being the major source above $50^{\circ}$ latitude in other years.
Also shown in Figure 5 are the sources due to $\mathrm{N}_{2} \mathrm{O}$ oxidation in the mesosphere and the source due to SPEs in the stratosphere. It is clear that in most years the SPE source of ON will dominate both the mesospheric NO production due to $\mathrm{N}_{2} \mathrm{O}$ oxidation, $7.6 \times 10^{30} \mathrm{NO}$ molecules $\mathrm{yr}^{-1}$, and the GCR source of NO which is concentrated mainly below about 40 $\mathrm{km}$. On the average the SPE source of NO in the stratosphere

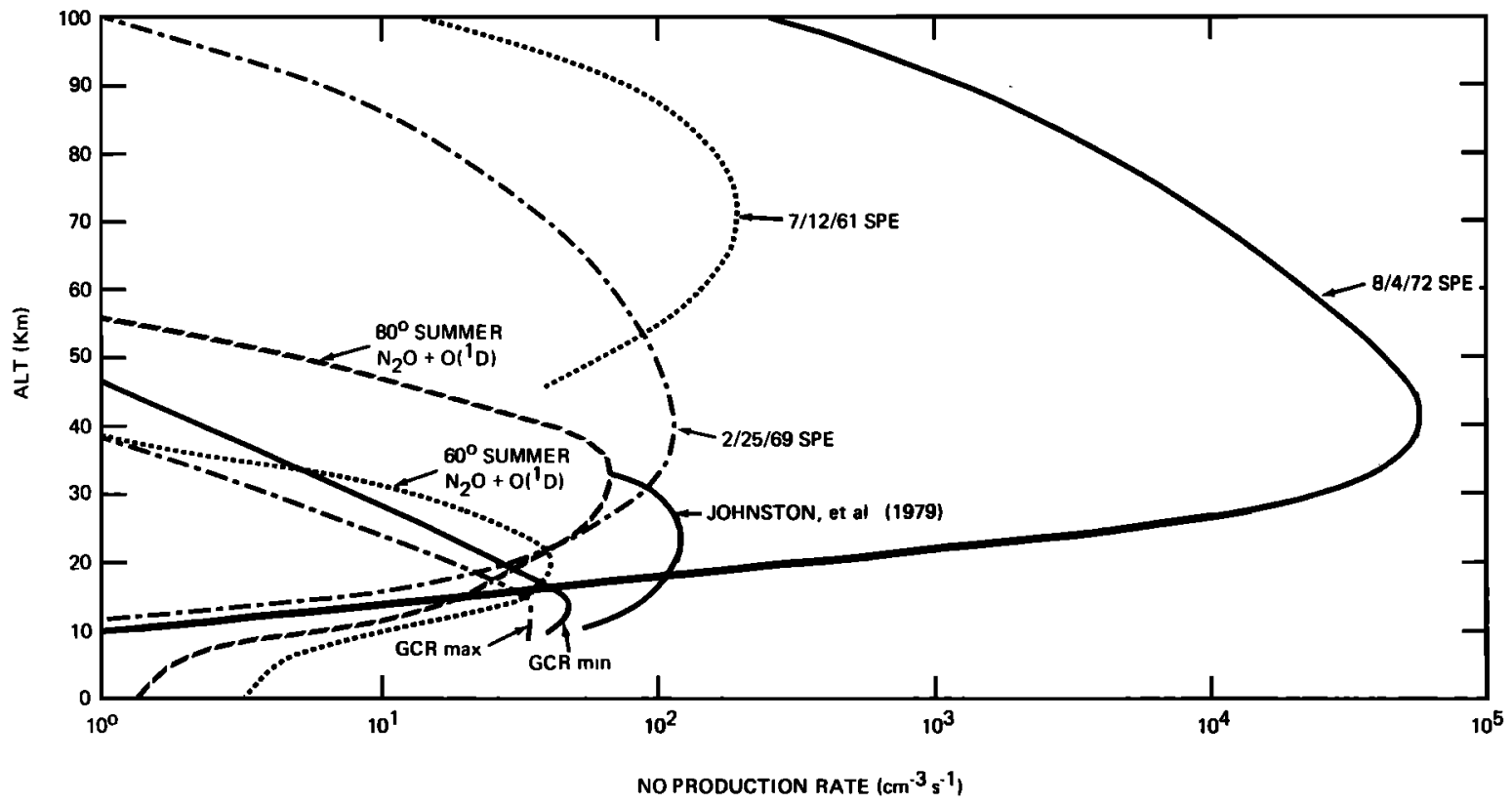

Fig. 4. Instantaneous nitric oxide production rates for GCRs (at solar maximum and minimum), SPEs (July 12, 1961, February 25, 1969, August 4, 1972), and oxidation of nitrous oxide (60 summer, $80^{\circ}$ summer and Johnston et al. [1979] at $60^{\circ}$ summer). 
is roughly $20 \%$ of the total SPE annual NO source, but this contribution can vary from 6 to $60 \%$. This stratospheric source in most years is smaller than that due to both $\mathrm{N}_{2} \mathrm{O}$ and GCRs, these sources being primarily stratospheric.

Several caveats should be given concerning the $\mathrm{N}_{2} \mathrm{O}$ oxidation source. If the $60^{\circ}$ latitude measurements of Schmeltekopf et al. [1977] are unrepresentative then that source should be somewhat larger than shown in Figure 5. A rough calculation using Johnston et al. [1979] gives a $\mathrm{N}_{2} \mathrm{O}$ source about twice our $\mathrm{N}_{2} \mathrm{O}$ source plotted in Figure 5. Also, the $\mathrm{N}_{2} \mathrm{O}$ source is shown as a constant throughout the $1954-1979$ period. The $\mathrm{N}_{2} \mathrm{O}$ source flux has probably been changing throughout this period [e.g., Sze and Rice, 1976; Liu et al., 1976; Crutzen, 1976; McElroy et al., 1976; Johnston, 1977; CAST, 1977; Liu et al., 1977], but because of the expected long lifetime of $\mathrm{N}_{2} \mathrm{O}(\sim 100$ yrs) these changes should not yet have appeared in the $\mathrm{N}_{2} \mathrm{O}$ concentration and hence the $\mathrm{ON}$ production rate. The $\mathrm{N}_{2} \mathrm{O}$ source may also show a solar cycle variation if upper stratospheric ozone has such a variation. Whether or not ozone varies significantly with solar activity is still an open question [e.g., London and Reber, 1979; Angell and Korshover, 1976;

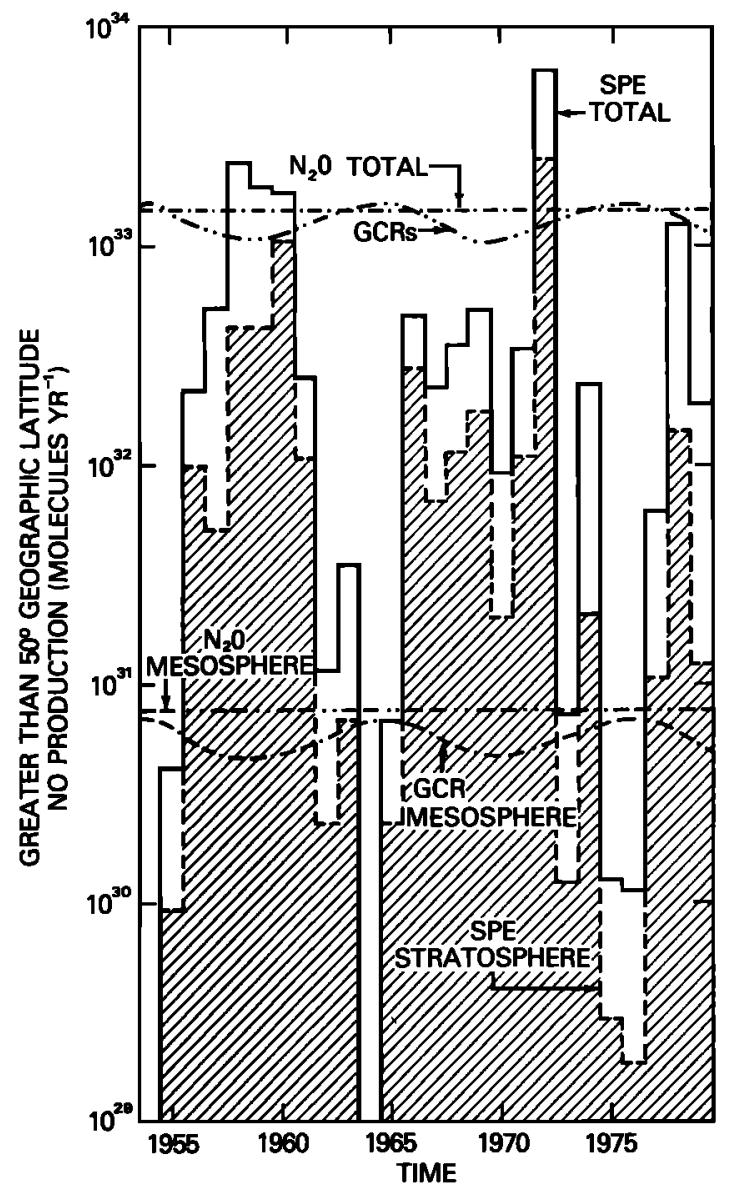

Fig. 5. Annual nitric oxide production rates for geographic latitudes above $50^{\circ}$. The solid line and dashed line histograms represent the solar proton event source in the stratosphere and mesosphere together and in the stratosphere alone, respectively. The dash-dot and double dash-double dot straight lines represent the oxidation of nitrous oxide source in the stratosphere and mesosphere together and in the mesosphere alone, respectively, while the dash-double dot and double dash-dot sinusoidal lines exhibit the galactic cosmic ray source in the stratosphere and mesosphere together and in the mesosphere alone, respectively.

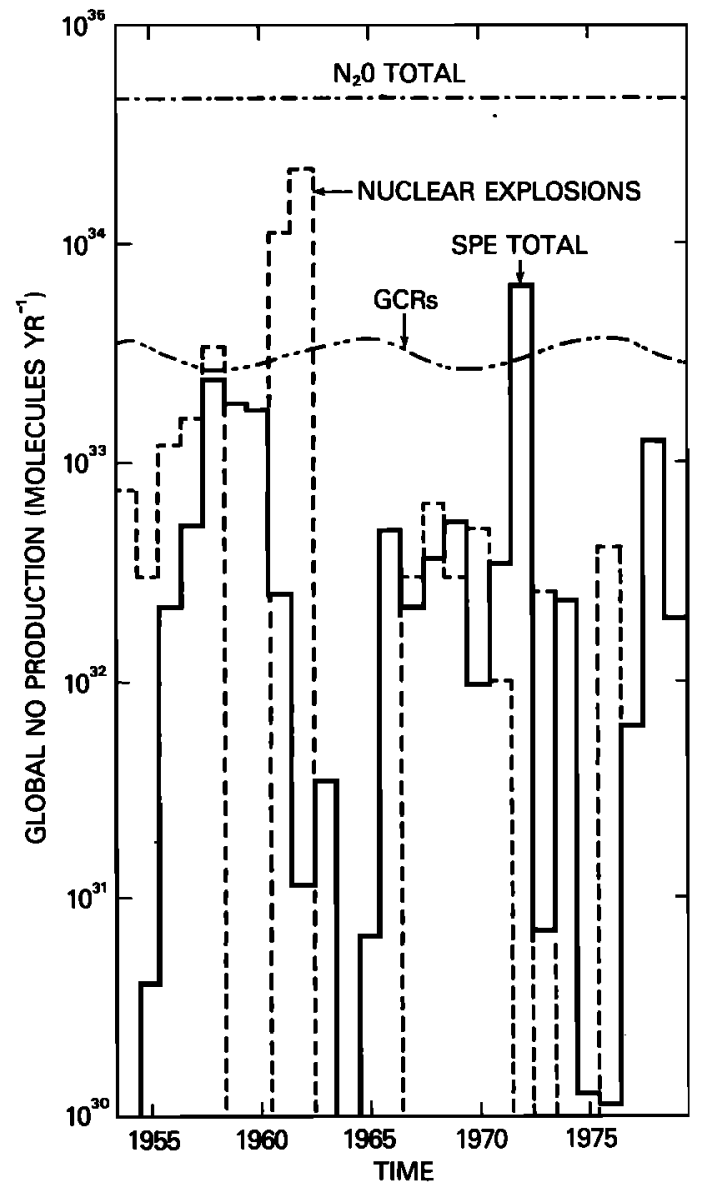

Fig. 6. Global annual stratosphere and mesosphere nitric oxide production rates. The solid lines and dashed line histograms represent the solar proton event and nuclear explosion sources, respectively. The dash-dot straight line and dash-double dot sinusoidal line exhibit the oxidation of nitrous oxide and the galactic cosmic ray sources, respectively.

Paetzold, 1973]. Thus for the purposes of the present comparison a constant $\mathrm{N}_{2} \mathrm{O}$ oxidation source should suffice.

Horizontal transport can have a significant effect on $O N$ due to its long lifetime in the stratosphere. This transport would redistribute the ON from SPEs formed in the polar cap regions down to the mid-latitudes [Frederick, 1976]. For this reason, Figure 6 shows a comparison of the ON sources on a global annual scale. In this context the ON sources from SPEs and GCRs are at least an order of magnitude smaller than the $\mathrm{N}_{2} \mathrm{O}$ oxidation source.

Thorne [1980] has estimated the production rate of $\mathrm{ON}$ in the mesosphere due to REPs to be $1.4 \times 10^{33}$ to $1.4 \times 10^{34}$ molecules $\mathrm{yr}^{-1}$. While the upper limit of this rate is higher than all other ON sources above $50^{\circ}$ latitude, $99.8 \%$ of this ON production occurs above $50 \mathrm{~km}$. If one accepts these numbers, the REPs are a significant, if not the dominant, ON source in the mesosphere.

\section{OTHER ON SOURCES}

Bauer [1979] has estimated the magnitude of stratospheric injections of ON due to past atmospheric nuclear explosions. The ON injection rate per year was calculated from these data and Figure 6 compares this with the global annual SPE, GCR, and $\mathrm{N}_{2} \mathrm{O}$ source of $\mathrm{ON}$. The stratospheric and mesospheric $\mathrm{N}_{2} \mathrm{O}$ oxidation source of $4.5 \times 10^{34} \mathrm{NO}$ molecules $\mathrm{yr}^{-1}$ is by 
TABLE 1. Listing and Comparison of ON Sources in the Stratosphere and Mesosphere

\begin{tabular}{|c|c|c|c|c|c|}
\hline Source & Area & Description & $\begin{array}{c}\text { Strato- } \\
\text { spheric } \\
\text { (S) Source } \\
\text { in ON } \\
\text { Molecules, } \\
\text { yr }^{-1}\end{array}$ & $\begin{array}{c}\text { Meso- } \\
\text { spheric } \\
\text { (M) Source } \\
\text { in ON } \\
\text { Molecules, } \\
\text { yr }^{-1}\end{array}$ & $\begin{array}{c}\text { S and } M \\
\text { Source } \\
\text { in ON } \\
\text { Molecules, } \\
\mathrm{yr}^{-1}\end{array}$ \\
\hline $\begin{array}{l}\mathrm{N}_{2} \mathrm{O}+\mathrm{O}\left({ }^{1} D\right) \\
\mathrm{N}_{2} \mathrm{O}+\mathrm{O}\left({ }^{1} D\right) \\
\text { GCRs } \\
\text { GCRs } \\
\text { GCRs } \\
\text { GCRs } \\
\text { REPs }\end{array}$ & $\begin{array}{l}\text { Global } \\
>50^{\circ} \\
\text { Global } \\
\text { Global } \\
>50^{\circ} \\
>50^{\circ} \\
\text { Global } \\
>50^{\circ}\end{array}$ & $\begin{array}{l}\text { average } \\
\text { average } \\
\text { solar maximum } \\
\text { solar minimum } \\
\text { solar maximum } \\
\text { solar minimum } \\
\text { maximum }\end{array}$ & $\begin{array}{l}4.5+34 \\
1.4+33 \\
2.7+33 \\
3.7+33 \\
1.1+33 \\
1.6+33 \\
2.7+31\end{array}$ & $\begin{array}{l}5.3+32 \\
7.6+30 \\
1.2+31 \\
1.6+31 \\
4.7+30 \\
7.0+30 \\
1.4+34\end{array}$ & $\begin{array}{l}4.5+34 \\
1.4+33 \\
2.7+33 \\
3.7+33 \\
1.1+33 \\
1.6+33 \\
1.4+34\end{array}$ \\
\hline REPs & $\begin{array}{l}\text { Global } \\
>50^{\circ}\end{array}$ & minimum & $2.7+30$ & $1.4+33$ & $1.4+33$ \\
\hline $\begin{array}{l}\text { Down flux from thermo- } \\
\text { sphere }\end{array}$ & Global & maximum & & $1.5+34$ & $1.5+34$ \\
\hline $\begin{array}{l}\text { Down flux from thermo- } \\
\text { sphere }\end{array}$ & Global & minimum & & $3.7+33$ & $3.7+33$ \\
\hline $\begin{array}{l}\text { Meteors } \\
\text { Lightning }\end{array}$ & $\begin{array}{l}\text { Global } \\
\text { Global }\end{array}$ & $\begin{array}{l}\text { average } \\
\text { average }\end{array}$ & & $6.3+32$ & $6.3+32$ \\
\hline Nuclear explosions & Global & maximum 1962 & $2.2+34$ & & $2.2+34$ \\
\hline SPEs & $\begin{array}{l}\text { Global } \\
>50^{\circ}\end{array}$ & maximum 1972 & $2.5+33$ & $3.9+33$ & $6.4+33$ \\
\hline
\end{tabular}

far the largest. The total atmospheric $\mathrm{N}_{2} \mathrm{O}$ oxidation source of $4.7 \times 10^{34} \mathrm{NO}$ molecules $\mathrm{yr}^{-1}$ compares quite favorably with the $4.5 \times 10^{34} \mathrm{NO}$ molecules $\mathrm{yr}^{-1}$ calculated by Johnston et al. [1979]. The other ON sources are at least 1 order of magnitude lower except in the years 1961 and 1962 when a large number of nuclear tests were conducted and 1.1 and $2.2 \times 10^{34} \mathrm{NO}$ molecules were added to the total global $O N$ content.

Lightning is another source of $\mathrm{ON}$, however; this production occurs in the troposphere where ON production is least efficient in affecting the middle atmosphere ON budget because of down drafts and rainout/washout processes. Thus this production rate of $1.6 \times 10^{36} \mathrm{ON}$ molecules $\mathrm{yr}^{-1}$ [Chameides et al., 1977], which could in principal dominate the total annual production rate, adds little $\mathrm{ON}$ to the middle atmosphere. Lightning may produce $\mathrm{N}_{2} \mathrm{O}$ [Griffing, 1977; Levine et $a l ., 1979]$, and thereby influence the ambient chemical source of NO.

The source of ON produced in the wake of large meteors could dominate all others in the middle atmosphere. Park [1978] estimated the production due to the Tunguska meteor of 1908 at $3.8 \times 10^{35}$ molecules of NO between 10 and $50 \mathrm{~km}$. In ordinary years, however, most of this production occurs above the mesopause with only about $6.3 \times 10^{32}$ molecules being produced annually in the mesophere. The $\mathrm{N}$ and NO produced above $86 \mathrm{~km}\left(7.7 \times 10^{33}\right.$ molecules $\left.\mathrm{yr}^{-1}\right)$ could add to the downward flux of NO from the thermosphere.

\section{NET NO FluX INTO THE MESOSPHERE}

Past theoretical studies indicate that downward transport of thermospheric nitric oxide provides a significant source of $\mathrm{ON}$ for the mesosphere. Values of the downward flux at the mesopause, based on model calculations, range from $1.5 \times 10^{7}$ $\mathrm{cm}^{-2} \mathrm{~s}^{-1}$ [McConnell and McElroy, 1973] to a maximum of 5.0 $\times 10^{8} \mathrm{~cm}^{-2} \mathrm{~s}^{-1}$ [Strobel, 1971]. If these values represent global averages, then the NO supplied to the mesosphere lies between $2.4 \times 10^{33}$ and $8.0 \times 10^{34}$ molecules $\mathrm{yr}^{-1}$. Figure 6 indicates that fluxes near the upper limit would constitute the major source of middle atmospheric $O N$. In any case, above
$45-50 \mathrm{~km}$ the ON source associated with nitrous oxide is small so that transport from the thermosphere likely supplies much of the ambient nitric oxide in the mesosphere. Note, however, that production of odd nitrogen in SPEs and REPs can be a locally significant, although sporadic, source at high latitudes.

Available measurements of nitric oxide allow an estimate of the downward flux from the thermosphere as follows. Over the altitude range $50-86 \mathrm{~km}$, the integrated chemical loss of ON is much greater than the production [Strobel, 1971; Brasseur and Nicolet, 1973]. Thus to an acceptable approximation the net flux into the region is balanced by in situ loss:

$$
-\phi_{\mathrm{ON}}=-\phi(z=86)+\phi(z=50)=\int_{z=50}^{86} d z^{\prime} L
$$

where $\phi_{\mathrm{ON}}$ is the NO flux measured positive upwards and $L$ is the loss rate due to

$$
\begin{aligned}
& \mathrm{N}+\mathrm{NO} \rightarrow \mathrm{N}_{2}+\mathrm{O} \\
& k_{5}=8.2 \times 10^{-11} \exp (-410 / T) \mathrm{cm}^{3} \mathrm{~s}^{-1}
\end{aligned}
$$

The only source of nitrogen atoms in the mesosphere, aside from sporadic energetic particles and meteors, is the predissociation of NO

$$
\mathrm{NO}+h \nu \rightarrow \mathrm{N}+\mathrm{O}
$$

Some of the $\mathrm{N}$ atoms produced in (6) reform $\mathrm{NO}$ in

$$
\begin{gathered}
\mathrm{N}+\mathrm{O}_{2} \rightarrow \mathrm{NO}+\mathrm{O} \\
k_{7}=5.5 \times 10^{-12} \exp (-3220 / T) \mathrm{cm}^{3} \mathrm{~s}^{-1}
\end{gathered}
$$

and

$$
\begin{aligned}
& \mathrm{OH}+\mathrm{N} \rightarrow \mathrm{NO}+\mathrm{H} \\
& k_{8}=5.3 \times 10^{-11} \mathrm{~cm}^{3} \mathrm{~s}^{-1}
\end{aligned}
$$

The reaction rate coefficient $k_{8}$ is taken from Hampson and Garvin [1978]. The reaction of atomic nitrogen with ozone is now thought to proceed so slowly as to be negligible (L. J. 
Stief, personal communication, 1979). The ON loss rate is then

$$
L=2 k_{5}[\mathrm{NO}][\mathrm{N}]=\frac{2 k_{5} J_{6}[\mathrm{NO}]^{2}}{k_{5}[\mathrm{NO}]+k_{7}\left[\mathrm{O}_{2}\right]+k_{8}[\mathrm{OH}]}
$$

The $\mathrm{O}_{2}$ model used in the calculation is derived from the U.S. Standard Atmosphere [1976] with the $\mathrm{OH}$ profile being taken from Herman [1979]. The NO dissociation rate, $J_{6}$, is that of Frederick and Hudson [1979] averaged over a diurnal cycle at $40^{\circ} \mathrm{N}$. Separate values of the loss rate and net flux were computed for summer and winter.

Two nitric oxide models have been constructed based on the few available measurements so as to span the likely range of variability. Model I represents a small NO content and is based on the data of Meira [1971] above $80 \mathrm{~km}$, where a factor of 2 correction required for the updated gamma band emission rate factor is included [Oran et al., 1975]. Below $60 \mathrm{~km}$ the profile is based on the data of Mason and Horvath [1977] and Horvath and Mason [1978]. Model I predicts a small upward flux at the stratopause with the NO mixing ratio decreasing from $\sim 8 \times 10^{-9}$ by volume at $50 \mathrm{~km}$ to $\sim 7 \times 10^{-9}$ at $65 \mathrm{~km}$. The steep mixing ratio increase above $80 \mathrm{~km}$ provides a substantial downward flux here. Model II, representing a large NO content, is based on the Meira [1971] profile above $80 \mathrm{~km}$ and has a constant mixing ratio of $2 \times 10^{-8}$ to the stratopause. In this case a large flux flows from the thermosphere to the mesosphere but the flux at the stratopause is zero.

Use of Models I and II each with the values of the NO dissociation rates for summer and winter produce the following. For summer

Model I

Model II

$$
\begin{aligned}
& -\phi_{\mathrm{ON}}=3.6 \times 10^{7} \mathrm{~cm}^{-2} \mathrm{~s}^{-1} \\
& -\phi_{\mathrm{ON}}=9.4 \times 10^{7} \mathrm{~cm}^{-2} \mathrm{~s}^{-1}
\end{aligned}
$$

and for winter

Model I

Model II

$$
-\phi_{\mathrm{ON}}=2.3 \times 10^{7} \mathrm{~cm}^{-2} \mathrm{~s}^{-1}
$$

$$
-\phi_{\mathrm{ON}}=5.6 \times 10^{7} \mathrm{~cm}^{-2} \mathrm{~s}^{-1}
$$

Inclusion of (8) in our calculations results in about a $10 \%-15 \%$ decrease in the NO flux required from the thermosphere. In all cases the results based on the NO models are bracketed by past theoretical predictions. If we adopt the Model I winter and Model II summer results as the extremes of a globally averaged downward flux at $85 \mathrm{~km}$, then the middle atmosphere receives between $3.7 \times 10^{33}$ and $1.5 \times 10^{34} \mathrm{NO}^{2}$ molecules $\mathrm{yr}^{-1}$ from the thermosphere. These values are between $8 \%$ and $33 \%$ of the source associated with $\mathrm{N}_{2} \mathrm{O}$ and are larger than the annual production due to GCRs and, in most years, SPEs. We note that the enhanced nitric oxide content of the lower thermospheric auroral zones [Rusch and Barth, 1975] may lead to enhanced fluxes at high latitudes which cannot be estimated with the steady state, globally averaged approach used above.

\section{CONCLUSIONS}

A comparison of the annual production rates from several ON sources appears in Table 1 . Where appropriate, the average annual production rate is given. When there is a range of ON production between solar maximum and minimum, the extreme values are listed. For REPs the values shown represent the uncertainty range given by Thorne [1980]. The range for the source of $\mathrm{ON}$ from the thermosphere was calculated in this work. The results for nuclear explosions and SPEs are for the years of largest annual production since 1954. For SPEs the minimum production is insignificant but greater than zero. In a global sense the oxidation of nitrous oxide exceeds any other stratospheric ON source by 1 order of magnitude or more. However, this process is much less efficient in the mesosphere. Only $1.2 \%$ of the global production of $\mathrm{ON}$ due to $\mathrm{N}_{2} \mathrm{O}$ oxidation occurs above $50 \mathrm{~km}$ and, under this circumstance, the downward flux from the thermosphere, REPs, and SPEs become the major mesospheric sources of ON.

In select years, the stratospheric production of $\mathrm{ON}$ due to SPEs can be comparable to that of $\mathrm{N}_{2} \mathrm{O}$ oxidation above latitude $50^{\circ}$. Hence, high latitude ON likely shows a substantial year-to-year variability related to solar activity. Since $O N$ has a long lifetime in the stratosphere, this variability should also appear at middle latitudes due to the action of horizontal transport. In the mesosphere the three largest sources of $\mathrm{ON}$ are linked to solar activity. The downward flux of nitric oxide at the mesopause should reflect variations in the thermosphere which are known to occur [Rusch and Barth, 1975] while the occurrences of REPs and SPEs are sporadic. The temporal behavior of these mesospheric sources suggests a large global scale variability in the $O N$ abundance above $50 \mathrm{~km}$ both in terms of the yearly average and on time scales comparable to the chemical lifetime.

\section{APPENDIX: TREATMENT OF SPEs}

In this appendix we express the spectrum of all SPEs in the same analytic form and quantify the $O N$ injection rate from SPES.

The energy loss $E_{L}$ by an isotropic flux $\Phi(E)$ in $\mathrm{cm}^{-2} \mathrm{sr}^{-1}$ $\mathrm{MeV}^{-1}$ of protons with kinetic energy $E$ in the $i$ th slab of a plane parallel atmosphere is

$$
E_{L}=\int_{0}^{\infty} \Phi(E) E_{L \lambda}(E) d E \quad \quad \mathrm{MeV} \mathrm{cm}^{-2} \mathrm{~s}^{-1}
$$

where $E_{L}(E)$ is the energy loss by a monoenergetic flux of protons of energy $E$. This integral equation requires the use of the well-known range energy relation [Whaling, 1958; Sternheimer, 1959; Green and Peterson, 1968]. For this work the range data of Sternheimer [1959] were fit by using

$$
R(E)=A\left(\frac{E}{1 \mathrm{MeV}}\right)^{B} \quad \mathrm{gm} \mathrm{cm}^{-2}
$$

with $A=2.71 \times 10^{-3}$ and $B=1.72$ for energies from 1 up to $1550 \mathrm{MeV}$ and with $A=0.834$ and $B=0.94$ for energies greater than $1550 \mathrm{MeV}$. These fits are good to within $16 \%$ at energies up to $10^{5} \mathrm{MeV}$ and to within 5\% at most energies. We assume isotropically directed incident particle fluxes. The energy range from $1-10^{4} \mathrm{MeV}$ is divided into 60 logarithmic intervals while the pitch angle range $0-\pi / 2$ radians is split into 35 equal intervals.

The atmosphere from 0-110 $\mathrm{km}$ was divided into slabs of 2 km thickness. The energy loss $E_{L i}(\theta, E)$ in the ith slab from a proton with pitch angle $\theta$ and kinetic energy $E$ could then be calculated from

$$
E_{L i}(\theta, E)=E-\left\{-\frac{\Delta Z_{i}}{A} \sec \theta+E^{B}\right\}^{1 / B} \mathrm{MeV}
$$




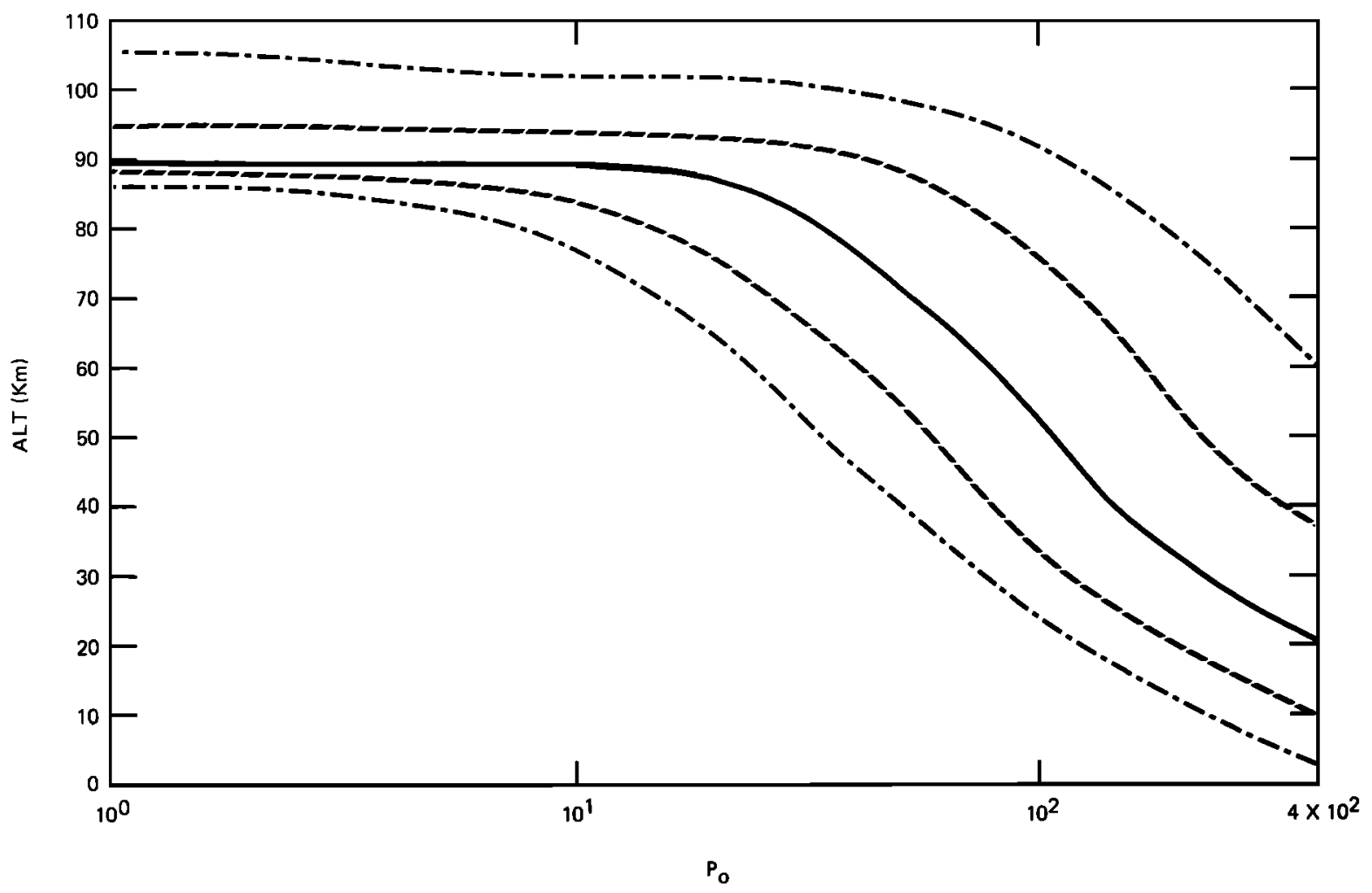

Fig. A1. The maximum intensity, $J_{P}$, and $e$ folding rigidity, $P_{0}$, for SPEs in the solar cycle from 1956 to 1967 are given.

where $\Delta Z_{i}$ is the atmospheric mass in $\mathrm{gm} \mathrm{cm}^{-2}$ contained in layer $i$. Finally, the energy loss $E_{L}(E)$ by an isotropic flux of monoenergetic protons over the upper hemisphere is found by integrating $E_{L}(\theta, E)$

$E_{L N}(E)=\int_{0}^{2 \pi} \int_{0}^{\pi / 2} \cos \theta E_{L}(\theta, E) \sin \theta d \theta \phi \quad \mathrm{MeV} \mathrm{sr}$

where $\phi$ is the azimuthal angle and $\theta$ the polar angle.

The $\mathrm{N}, \mathrm{N}^{+}, \mathrm{O}, \mathrm{O}^{+}$, and ion pairs produced in the ith slab can be calculated by using the energy loss per specie given in Porter et al. [1976]. In large SPEs enough $\mathbf{N}$ atoms are created to cause (5) to be quite important (e.g., August 1972 SPEs) as a loss for ON species. Here, we ignore this loss and assume that 1.25 NO molecules are produced per ion pair [Jackman et al., 1979].

Previous studies have used several different analytic forms to characterize the energy spectra of SPEs [Freier and Webber, 1963; Zmuda and Potemra, 1972]. Here we choose a differential spectrum which is exponential in rigidity

$$
\Phi(P)=J_{P} \exp \left(-P(E) / P_{0}\right) \mathrm{cm}^{-2} \mathrm{~s}^{-1} \mathrm{sr}^{-1} \mathrm{MeV}^{-1}
$$

where $P(E)=p c / q=\left(E^{2}+2 E m_{0} c^{2}\right)^{1 / 2}$ with $p=$ the momentum, $c=$ the speed of light, $m_{0}=$ the mass of a proton, $E=$ the kinetic energy of the proton, and $q=1$ for the charge on protons. We also assume that the $e$ folding rigidity, $P_{0}$ does not change during the event. The intensity is assumed to be timedependent with an exponential rise of $\exp \left(t / T_{1}\right)$, where $t$ is the time in hours from the initiation of the event up to the peak intensity, $J_{p}$, at time $T_{\max }$. The intensity fall off has an $\exp (-t /$ $T_{2}$ ) shape where $t$ here is the time in hours from $T_{\max }$ up to $T_{D}$, the duration of the event. Use of this time-dependent spectral form requires the six parameters $P_{0}, J_{P}, T_{1}, T_{2}, T_{\max }$ and $T_{D}$.
Through this form many SPE proton spectra from the years 1954-1979 were characterized. Figure Al relates $J_{P}$ and $P_{0}$ for a solar cycle from 1956 through 1967 . Generally, the lower the value of $J_{P}$ the higher the $e$ folding rigidity $P_{0}$. The altitude of ON production is important in determining the total net $O N$ actually added to the atmosphere. Figure A2 presents the altitude of energy deposition as a function of the $e$ folding rigidity $\boldsymbol{P}_{0}$. The solid line shows the altitude of maximum NO production, the dashed lines indicate the altitudes of one half the maximum production and the dash-dot lines represent the altitudes of one tenth the maximum production. It was found at all values of $P_{0}$ that $70 \%-80 \%$ of the total NO production was between the one-half maximum values and that $97 \%-99 \%$ of the total NO production was between the one-tenth maximum value points.

Data to obtain the six parameters $\left(P_{0}, J_{P}, T_{1}, T_{2}, T_{\max }\right.$, and $\left.T_{D}\right)$ needed to characterize each SPE were taken from several sources. Svestka and Simon [1975] present data on 352 events that have occurred in the time frame from 1955 through 1969. For each event they give the total duration time, $T_{D}$, and the Smart and Shea [1971] index numbers which are an indirect measure of the intensity and rigidity of the event. Information from the Solar-Geophysical Data was taken for SPEs in the time frame from May 1967 through August 1972. Freier and Webber [1963] provided $J_{P}$ and $P_{0}$ information for SPEs occurring from 1956 through 1961. Bailey [1964] gave intensity, $T_{\max }$ and $T_{D}$ information. Zmuda and Potemra [1972] gave peak spectral information which could easily be converted to give the $P_{0}$ and $J_{P}$ needed in (A5). Detailed information about SPEs was available, using the proton flux data from the Goddard Space Flight Center experiment on the IMP 7 (19731977) and IMP 8 (1978 and 1979) satellites (R. E. McGuire, T. T. von Rosenvinge, and F. B. McDonald, private communication, 1979). These data were used to give values for all six 


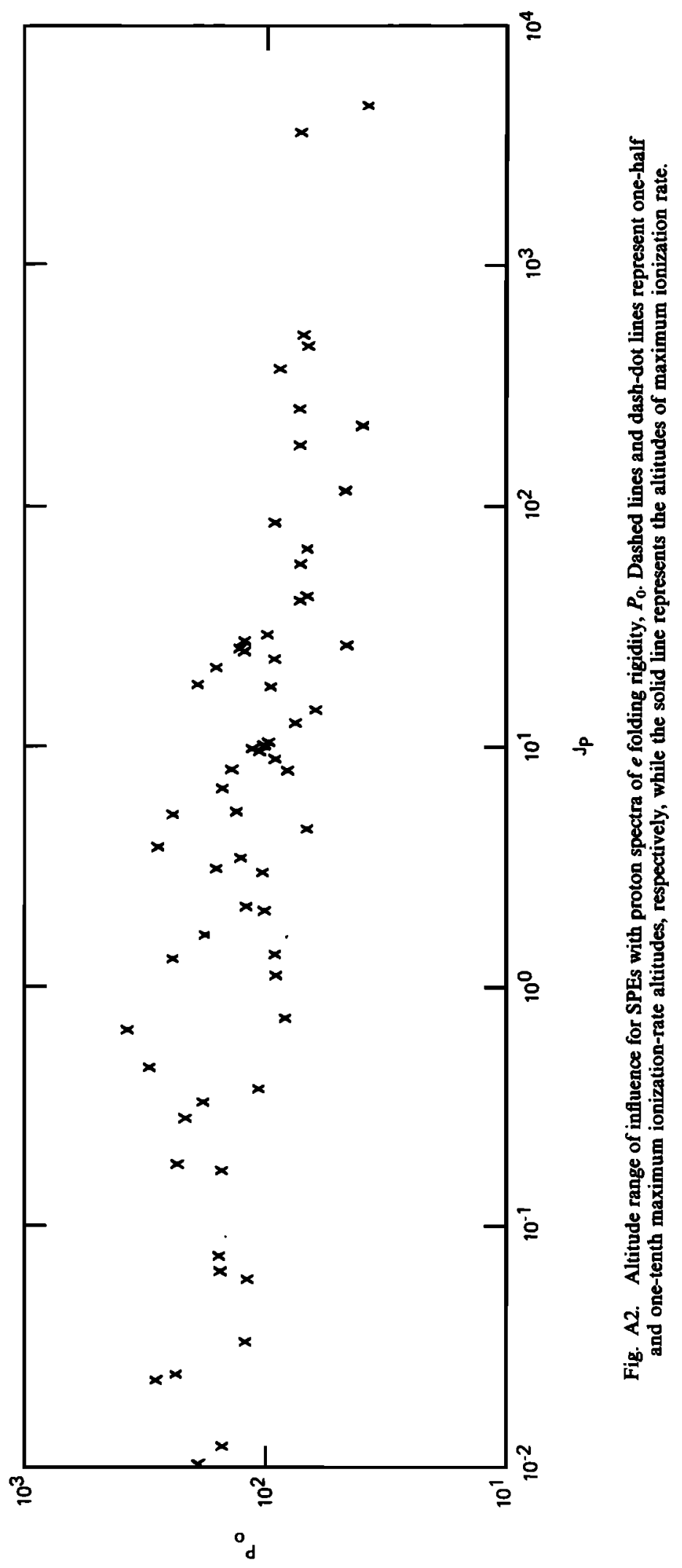


parameters needed to characterize the time dependency of each SPE proton spectrum.

Some time integral information is available about proton fluxes of the SPEs. King [1974] provides this information for several SPEs occurring in the time period from July 1966 through August 1972. These data were used to derive a $J_{P}$ and $P_{0}$ for a time integral form of (A5). We obtain further integral information by using ion pair production profiles provided in Bauer [1978] for the SPEs occurring in February 1956, November 1960, September 1966, and August 1972.

Where information was not available concerning each of the six time-dependent spectrum parameters, the parameters from known SPEs, which had similar characteristics, including the Smart and Shea index, duration of the event, and the peak intensity of protons with energies greater than $10 \mathrm{MeV}$, were used to infer the remaining unknown parameters. There is a large uncertainty in this approach for several reasons, three of which are (1) the $e$ folding rigidity, $P_{0}$, is not constant throughout the event; (2) the time dependency cannot always be described appropriately with an exponential increase and decrease; and (3) SPEs with similar Smart and Shea indices, time duration, and/or peak intensity of protons with energies $>10 \mathrm{MeV}$ may not have the same time-dependent spectrum parameters, in general. The data are quite good for SPEs that have occurred since October 1972, thus a more exact approach may be used in future work to describe the time-dependent NO production rate.

Acknowledgments. The authors would like to acknowledge the help of J. R. Herman and C. J. McQuillan (Goddard Space Flight Center) in setting up the multiple scattering technique used in this paper. We thank R. E. McGuire who was of great assistance in obtaining SPE proton spectrum data for the years since 1972. We would also like to acknowledge the useful discussions and/or correspondence with R. W. Nightingale (Lockheed Palo Alto Research Laboratory), E. Bauer (Institute for Defense Analyses), and H. S. Porter (Furman University) on SPEs and their effects on the atmosphere. CHJ wishes to thank the National Academy of Sciences for a resident research associateship at the Goddard Space Flight Center during which this work was carried out.

\section{REFERENCES}

Ackerman, M., Ultraviolet solar radiation related to mesospheric processes, in Mesospheric Models and Related Experiments, edited by G. Fiocco, pp. 149-159, D. Reidel, Hingham, Mass., 1971.

Angell, J. K., and J. Korshover, Global analysis of recent total ozone fluctuations, Mon. Weather Rev., 104, 63-75, 1976.

Bailey, D. K., Polar-cap absorption, Planet. Space Sci, 12, 495-541, 1964.

Bates, D. R., Some reactions occurring in the earth's upper atmosphere, Ann. Geophys., 8, 194-204, 1952.

Bates, D. R., and P. B. Hays, Atmospheric nitrous oxide, Planet. Space Sci., 15, 189-197, 1967.

Bauer, E., A catalog of perturbing influences on stratospheric ozone, 1955-1975, Pap. P-1340, Institute for Defense Analysis, Washington, D. C., 1978.

Bauer, E., A catalogue of perturbing influences on stratospheric ozone, 1955-1975, J. Geophys. Res., 84, 6929-6940, 1979.

Brasseur, G., and M. Nicolet, Chemospheric processes of nitric oxide in the mesosphere and stratosphere, Planet. Space Sci., 21, 939-961, 1973.

CAST, Effect of increased nitrogen fixation on stratospheric ozone, Rep. 53, Dep. of Agronomy, Iowa State Univ., Ames, Jowa, 1976.

Chameides, W. L., D. H. Stedman, R. R. Dickerson, D. W. Rusch and R. J. Cicerone, $\mathrm{NO}_{x}$ production in lightning, J. Atmos. Sci., 34, 143-149, 1977.

Crutzen, P. J., The influence of nitrogen oxides on the atmospheric ozone content, Quart. J. Roy. Meteorol. Soc., 96, 320-325, 1970.

Crutzen, P. J., Ozone production rates in an oxygen-hydrogen-nitrogen oxide atmosphere, J. Geophys. Res., 76, 7311-7327, 1971.
Crutzen, P. J., Upper limits on atmospheric ozone reductions following increased application of fixed nitrogen to the soil, Geophys. Res. Lett., 3, 169-172, 1976.

Crutzen, P. J., I. S. A. Isaksen, and G. C. Reid, Solar proton events: Stratospheric sources of nitric oxide, Science, 189, 457-459, 1975.

Dütsch, H. U., The ozone distribution in the atmosphere, Can. $J$. Chem., 52, 1491-1504, 1974.

Fabian, P., R. Borchers, K. H. Weiler, U. Schmidt, A. Volz, D. H. Ehhalt, W. Seiber, and F. Müller, Simultaneously measured vertical profiles of $\mathrm{H}_{2}, \mathrm{CH}_{4}, \mathrm{CO}, \mathrm{N}_{2} \mathrm{O}, \mathrm{CFCl}_{3}$, and $\mathrm{CF}_{2} \mathrm{Cl}_{2}$ in the mid-latitude stratosphere and troposphere, $J$. Geophys. Res., 84, 3149-3154, 1979a.

Fabian, P., J. A. Pyle, and R. J. Wells, The August 1972 solar proton event and the atmospheric ozone layer, Nature, 277, 458-460, 1979b.

Foley, H. M., and Ruderman, M. A., Stratospheric NO production from past nuclear explosions, J. Geophys. Res., 78, 4441-4450, 1973.

Frederick, J. E., Solar corpuscular emission and neutral chemistry in the earth's middle atmosphere, J. Geophys. Res., 81, 3179-3185, 1976.

Frederick, J. E., and R. D. Hudson, Predissociation of nitric oxide in the mesosphere and stratosphere, J. Atmos. Sci., 36, 737-745, 1979.

Freier, P. S., and W. R. Webber, Exponential rigidity spectrums for solar-flare cosmic rays, J. Geophys. Res., 68, 1605-1629, 1963.

Gilmore, F. R., The production of nitrogen oxides by low-altitude nuclear explosions, J. Geophys. Res., 80, 4553-4554, 1975.

Goldan, P. D., W. C. Kuster, D. L. Albritton, and A. L. Schmeltekopf, Stratospheric $\mathrm{CFCl}_{3}, \mathrm{CF}_{2} \mathrm{Cl}_{2}$, and $\mathrm{N}_{2} \mathrm{O}$ height profile measurements, J. Geophys. Res., 85, 413-423, 1980.

Green, A. E. S., and L. R. Peterson, Energy loss functions for electrons and protons in planetary gases, J. Geophys. Res., 73, 233-241, 1968.

Griffing, G. W., Ozone and oxides of nitrogen production during thunderstorms, J. Geophys. Res., 82, 943-950, 1977.

Hampson, R. F., and D. Garvin (Ed.), Reaction Rate and Photochemical Data for Atmospheric Chemistry-1977, NBS Spec. Publ. 513, National Bureau of Standards, Washington, D. C., 1978.

Heath, D. F., A. J. Krueger, and P. J. Crutzen, Solar proton event: influence on stratospheric ozone, Science, 197, 886-889, 1977.

Herman, J. R., The response of stratospheric constituents to a solar eclipse, sunrise, and sunset, J. Geophys. Res., 84, 3701-3710, 1979.

Horvath, J. J., and C. J. Mason, Nitric oxide mixing ratios near the stratopause measured by a rocket-borne chemiluminescent detector, Geophys. Res. Lett., 5, 1023-1026, 1978.

Hudson, R. D., (Ed.), Chloroflouromethanes and the Stratosphere, NASA Ref. Publ. 1010, 1977.

Jackman, C. H., H. S. Porter, and J. E. Frederick, Upper limits on production rate of NO per ion pair, Nature, 280, 170, 1979.

Johnston, H. S., Reduction of stratospheric ozone by nitrogen oxide catalysts from supersonic transport exhaust, Science, 173, 517-522, 1971.

Johnston, H. S., Analysis of the independent variables in the perturbation of stratospheric ozone by nitrogen fertilizers, $J$. Geophys. Res., 82, 1767-1772, 1977.

Johnston, H. S., and G. Whitten, Chemical reactions in the atmosphere as studied by the method of instantaneous rates, Int. J. Chem. Kinet., Symp. 1, 1-26, 1975.

Johnston, H. S., O. Serang, and J. Podolske, Instantaneous global nitrous oxide photochemical rates, J. Geophys. Res., 84, 5077-5082, 1979.

Johnston, H., G. Whitten, and J. Birks, Effect of nuclear explosions on stratospheric nitric oxide and ozone, J. Geophys. Res., 78, 6107$6135,1973$.

King, J. H., Solar proton influences for $1977-1983$ space missions, $J$. Spacecrafis Rockets, 11, 401-408, 1974.

Levine, J. S., R. S. Hughes, W. L. Chameides, and W. E. Howell, $\mathrm{N}_{2} \mathrm{O}$ and $\mathrm{CO}$ production by electric discharge: Atmospheric implications, Geophys. Res. Lett., 6, 557-559, 1979.

Liu, S. C., R. J. Cicerone, T. M. Donahue, and W. L. Chameides, Limitation of fertilizer induced ozone reduction by the long lifetime of the reservoir of fixed nitrogen, Geophys. Res. Lett., 3, 157-160, 1976.

Liu, S. C., R. J. Cicerone, T. M. Donahue, and W. L. Chameides, Sources and sinks of atmospheric $\mathrm{N}_{2} \mathrm{O}$ and the possible ozone reduction due to industrial fixed nitrogen fertilizers, Tellus, 29, 251263, 1977. 
London, J., and C. A. Reber, Solar activity and total atmospheric ozone, Geophys. Res. Lett., 6, 869-872, 1979.

London, J., J. E. Frederick, and G. P. Anderson, Satellite observations of the global distribution of stratospheric ozone, $J$. Geophys. Res., 82, 2543-2556, 1977.

Mason, C. J., and J. J. Horvath, The direct measurement of nitric oxide concentration in the upper atmosphere by a rocket-borne chemiluminescent detector, Geophys. Res. Lett., 3, 391-394, 1976.

McConnell, J. C., and M. B. McElroy, Odd nitrogen in the atmosphere, J. Atmos. Sci., 30, 1465-1480, 1973.

McElroy, M. B., and J. C. McConnell, Nitrous oxide: A natural source of stratospheric NO, J. Atmos. Sci., 28, 1095-1098, 1971.

McElroy, M. B., J. W. Elkins, S. C. Wofsy, and Y. L. Yung, Sources and sinks for atmospheric $\mathrm{N}_{2} \mathrm{O}$, Rev. Geophys. Space Phys., 14, 143150, 1976.

Meira, L. G., Jr., Rocket measurements of upper atmospheric nitric oxide and their consequences to the lower ionosphere, J. Geophys. Res., 76, 202-212, 1971.

Nicolet, M., Nitrogen oxides and the airglow, J. Atmos. Terr. Phys., 7, 297-309, 1955.

Nicolet, M., Aeronomic chemical reactions, in The Physics and Medicine of the Atmosphere and Space, edited by O. D. Benson, Jr. and H. Strughold, pp. 14 47, John Wiley, New York, 1960.

Nicolet, M., Aeronomic reactions of hydrogen and ozone, in Mesospheric Models and Related Experiments, edited by G. Fiocco, D. Reidel Co., Hingham, Mass., 1971.

Nicolet, M., On the production of nitric oxide by cosmic rays in the mesosphere and stratosphere, Planet. Space Sci., 23, 637-649, 1975a.

Nicolet, M., Stratospheric ozone: An introduction to its study, Rev. Geophys. Space Phys., 13, 593-636, 1975 b.

Nicolet, M., and W. Peetermans, The production of nitric oxide in the stratosphere by oxidation of nitrous oxide, Ann. Geophys., 28, 751761, 1972.

Oran, E. S., P. S. Julienne, and D. F. Strobel, The aeronomy of odd nitrogen in the thermosphere, $J$. Geophys. Res., 80, 3068-3076, 1975.

Paetzold, H. K., The influence of solar activity on the stratospheric ozone layer, Pure Appl. Geophys., 106-108, 1308-1311, 1973.

Park, C., Tunguska event produced nitric oxide, Eos Trans. AGU, 59, $1078,1978$.

Park, C., and G. P. Menees, Odd nitrogen production by meteoroids, J. Geophys. Res., 83, 4029-4035, 1978.

Porter, H. S., C. H. Jackman, and A. E. S. Green, Efficiencies for production of atomic nitrogen and oxygen by relativistic proton impact in air, J. Chem. Phys., 65, 154-167, 1976.

Reagan, J. B., R. W. Nightingale, R. E. Meyerott, R. C. Gunton, R. G. Johnson, J. E. Evans, and W. L. Imhof, Effects of the August 1972 solar particle events on stratospheric ozone, LMSC-D630455, Lockheed Palo Alto Res. Lab., Palo Alto, Calif., 1978.

Reid, G. C., A study of the enhanced ionization produced by solar protons during a polar cap absorption event, J. Geophys. Res., 66, 4071-4085, 1961.

Rundel, R. D., Determination of diurnal average photodissociation rates, J. Atmos. Sci., 34, 639-641, 1977.
Rusch, D. W., Satellite ultraviolet measurements of nitric oxide fluorescence with a diffusive transport model, J. Geophys. Res., 78, 5676-5686, 1973.

Rusch, D. W., and C. A. Barth, Satellite measurements of nitric oxide in the polar region, J. Geophys. Res., 80, 3719-3721, 1975.

Schmeltekopf, A. L., D. L. Albritton, P. J. Crutzen, P. D. Goldan, W. J. Harrop, W. R. Henderson, J. R. McAfee, M. McFarland, H. Schiff, T. L. Thompson, D. J. Hoffman, and N. T. Kjome, Stratospheric nitrous oxide profiles at various latitudes, J. Atmos. Sci., 34, 729-736, 1977.

Smart, D. F., and M. A. Shea, Solar proton event classification system, Solar Phys., 16, 484-487, 1971.

Solar-Geophysical Data, National Oceanic and Atmospheric Administration, Environmental Data Service, Boulder, Colo., May 1967August 1972.

Sternheimer, R. M., Range-energy relations for protons in $\mathrm{Be}, \mathrm{C}, \mathrm{Al}$, $\mathrm{Cu}, \mathrm{Pb}$, and air, Phys. Rev., 115, 137-142, 1959.

Strobel, D. F., Odd nitrogen in the mesosphere, J. Geophys. Res., 76, 8384-8393, 1971.

Strobel, D. F., D. M. Hunten, and M. B. McElroy, Production and diffusion of nitric oxide, J. Geophys. Res., 75, 4307-4321, 1970.

Strobel, D. F., E. S. Oran, and P. D. Feldman, The aeronomy of odd nitrogen in the thermosphere, 2, Twilight emissions, J. Geophys. Res., 81, 3745-3752, 1976.

Svestka, Z., and P. Simon, Catalog of Solar Particle Events 1955-1969, D. Reidel, Hingham, Mass., 1975.

Swider, W., and T. J. Keneshea, Decrease of ozone and atomic oxygen in the lower mesosphere during a PCA event, Planet. Space Sci., 21, 1969-1973, 1973

Sze, N. D., and $\mathrm{H}$. Rice, Nitrogen cycle factors contributing to $\mathrm{N}_{2} \mathrm{O}$ production from fertilizers, Geophys. Res. Lett., 3, 343-346, 1976.

Thorne, R. M., Energetic radiation belt electron precipitation: A natural depletion mechanism for stratospheric ozone, Science, 195, 287289, 1977.

Thorne, R. M., The importance of energetic particle precipitation on the chemical composition of the middle atmosphere, Pure Appl. Geophys., in press, 1980.

U.S. Standard Atmosphere, Publ. NOAA-S/f-1562, NOAA, Washington, D. C., 1976.

Warneck, P., Cosmic radiation as a source of odd nitrogen in the stratosphere, J. Geophys. Res., 77, 6589-6591, 1972.

Weeks, L. H., R. S. Cuikay, and J. R. Corbin, Ozone measurements in the mesosphere during the solar proton event of 2 November 1969 , J. Atmos. Sci., 29, 1138-1142, 1972.

Whaling, W., The energy loss of charged particles in matter, in Ency. clopedia of Physics, edited by S. Fluegge, 34, 193-217, SpringerVerlag, Berlin, 1958.

Zmuda, A. J., and T. A. Potemra, Bombardment of the polar-cap ionosphere by solar cosmic rays, Rev. Geophys. Space Phys., 10, 981991, 1972

(Received January 10, 1980;

revised May 19, 1980;

accepted May 23, 1980.) 